\title{
Residual life estimation of healthy and cracked composite beam using experimental and numerical modal analysis methods
}

Gedela RAMPRASAD, Shinigam RAMAKRISHNA

DOI: 10.30464/jmee.2020.4.2.127

Cite this article as:

Ramprasad G., Ramakrishna S. Residual life estimation of healthy and cracked composite beam using experimental and numerical modal analysis methods. Journal of Mechanical and Energy Engineering, Vol. 4(44), No. 2, 2020, pp. 127-134.

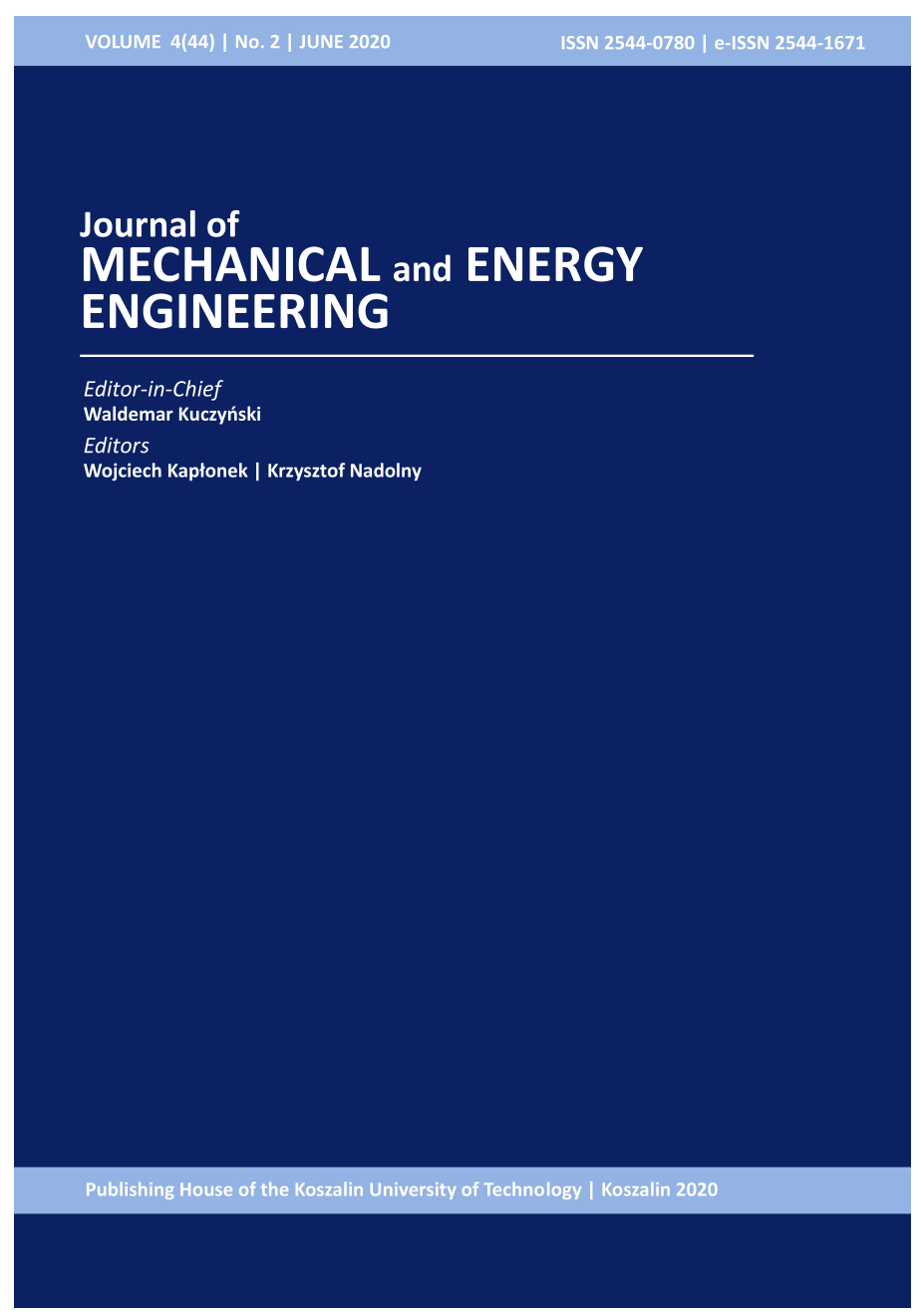

Journal of Mechanical and Energy

Engineering

Website: jmee.tu.koszalin.pl

ISSN (Print): 2544-0780

ISSN (Online): 2544-1671

Volume: 4(44)

Number: 2

Year: 2020

Pages: $127-134$

Article Info:

Received 16 June 2020

Accepted 1 July 2020

Open Access

This article is distributed under the terms of the Creative Commons Attribution 4.0 (CC BY 4.0) International License (http://creativecommons.org/licenses/by/4.0/), which permits unrestricted use, distribution, and reproduction in any medium, provided you give appropriate credit to the original author(s) and the source, provide a link to the Creative Commons license, and indicate if changes were made. 


\title{
RESIDUAL LIFE ESTIMATION OF HEALTHY AND CRACKED COMPOSITE BEAM USING EXPERIMENTAL AND NUMERICAL MODAL ANAL YSIS METHODS
}

\author{
Gedela RAMPRASAD ${ }^{1 *}$, Shinigam RAMAKRISHNA ${ }^{2}$ \\ ${ }^{1 *}$ Department of Mechanical Engineering, Gayatri Vidya Parishad College of Engineering, Visakhapatnam, \\ Andhra Pradesh, India, e-mail: ramprasad.mech321@gmail.com. \\ ${ }^{2}$ Department of Mechanical Engineering, Gayatri Vidya Parishad College of Engineering,Visakhapatnam, \\ Andhra Pradesh, India
}

(Received 16 June 2020, Accepted 1 July 2020)

\begin{abstract}
Preventive maintenance is beneficial to minimize unexpected breakdowns in industries with continuous production. Composite structures are used for naval applications like ship hulls and marine propellers. In most of the industries, composite structural health analysis using experimental and numerical model are available for damage detection and estimate the residual life of composite beams. The present work is focusses on identification of damage and estimate residual life of composite healthy and cracked beams. Free vibrational analysis is carried out on composite beam made of Glass fiber reinforced polymer (GFRP) with a different crack orientation. A Fast Fourier Transform (FFT) spectrum analyzer associated with engineering data management (EDM) software utilized for experimental analysis to detect presence of damage in cracked composite beam. Finite element method (FEM) software called Analysis of composite pre/post (ACP) available in ANSYS R3 is used to compare the natural frequency results of healthy composite beam with cracked composite beam with different ply orientations. For validation of numerical modal evaluation, the consequences acquired from ANSYS R3 Finite element analysis (FEA) software are in comparison with experimental results received by impact hammer method. The fatigue life of a damaged composite beam is estimated the use of "Hwang and Han's" fatigue life equation.
\end{abstract}

Keywords: E-glass/Epoxy fiber, composite healthy beam, composite cracked beam, Mode shape, Natural frequency, FFT Analysis, Crack location, ACP (pre\& post).

\section{INTRODUCTION}

Structural health monitoring is a concept of identifying damage location and strategizing its characteristics in engineering structures. In other words, health monitoring of machine elements or structures is procedure wherein certain methodologies are executed for the discovery of damage, location. These parameters vary between damaged and undamaged structures. Crack formation due to repetitive loads ends in fatigue of the structure. Hence crack detection plays an essential position in structural health monitoring programs. There is different nondestructive testing methods such as flaw detection C- scan are available for earlier damage detection in composite structures. But they are very expensive, time-consuming and some of them are difficult to implement for complex structures such as aircrafts, railway tracks, long columns, and long pipelines in power plants. Vibration testing has become a standard procedure for fault diagnosis in many applications. Due to the excellent mechanical properties, fiber reinforced composites are widely utilized in industry. Many fatigue specimens for fiber reinforced composite substances had been advanced, and can be classed into three categories: fatigue existence models based at the comparing three models, $\mathrm{S}-\mathrm{N}$ curves are base for fatigue lifestyle evaluation in fiber 
strengthened composite structure. Too many fatigue experiments are necessary to devise $\mathrm{S}-\mathrm{N}$ curves that is time consuming. Multi-axial fatigue life prediction can reduce time because of composite anisotropy and make contact with between the composite systems. Sufficient quantity of literature was available on fatigue behavior of GFRP epoxy composite substances. Equation is further simplified by strain failure criterion for realistic application.

\section{LITERATURE REVIEW}

From existing literature, it is evident that both experimental and numerical models are available to detect damage and estimate residual life in structure Pratibha [1] said an experimental modal analysis to discover crack place and size in cracked composite beam the usage of their first three natural frequencies in FFT analyzer. These results are validated with natural frequencies received from finite element technique in ANSYS software. Santiuste [2] tested the impact of experimental parameters namely wide variety of layers, fiber orientation and boundary situations at the natural frequency of woven fiber composite plate using FFT analyzer. [3, 4] they as investigated on natural frequency characteristics of quasi isotropic carbon fiber reinforced polymer (CFRP) with containing different hole location specimens. Decrease of the specimen natural frequencies based on increase number of holes and size. Cui [5] numerical study on modal frequency behaviour and structural dynamics of combining composite turbine blade. Pushparaj [6] analyzed the influence of hybridization, matrix fabric and fiber orientation on modal frequencies of GFRP and CFRP composites and also studied the mode shapes using experimental and computational procedures at different fiber volume fractions [7]. Chaudhari [8] performed modal analysis on isotropic right triangular composite plate made of materials like rubber, plastic and fiber reinforced polymers (FRP). The experimental results are compared with that obtained from fem analysis. More [9] compared finite element analysis and experimental modal analysis to detect damage in fiber reinforced composites and noncomposite structures. Sharayu [10] calculated natural frequency of different modes of a cantilever beam analytically and experimentally to find the effect of fiber orientation and aspect ratio of woven fiber composite plates in free-free boundary condition. Reddy [11] performed analytical studies on four different materials of transmission shaft in rear wheel drive automobile. They designed drive shaft in ANSYS ACP and in comparison natural frequencies of various substances the use of ANSYS static structural. Vader [12] evaluated changes in natural frequencies of cracked composite beam both experimentally and numerically. They conducted experiments to find frequencies in cracked beam using vibration analyzer with data acquisition system. They also modelled cracked structure in harmonic response module of ANSYS workbench and found to be close with experimental results. Stevan [13] developed a powerful and reliable computational approach for residual life estimation of cracked aircraft structural additives with recognize to fracture mechanics and the modal frequency of the cantilever beam will increase while the crack orientation with appreciate to the transverse axis is increased. Xe [14] conducted on vibration characteristics of woven fiber composite beam with different thickness is prepared by mixing of fiber volume fraction and epoxy resin curing ratio. The results observed from the experimental, strength depends on the fiber volume fraction and resin area in composite beam. Kale [15] studied on natural frequency characteristics of combined titanium alloy with CFRP turbine blade. Equal composition of material more stiffness and increases the weight of blade. [16] Studied about the residual strength of glass composite beam with the influence of impact strength, beam width and nose geometry of experimental specimens. The residual strength lower value at prepare the charpy nose compare to the hemispherical nose impactor. Prenil [17] predicative study on strength and failure analysis of modern composite turbine. Strength depend upon fiber orientation and layer stacking sequence order. Syayuthi [18] investigation of fatigue behavior of glass fiber reinforced epoxy composite material under different stress ratio. The fatigue behaviour majorly depend upon the variation of load and stress ratio. Wei [19] predict the fatigue life based on different ply angles and lay up order to sequence in-plane, longitudinal and transverse shear directions of composite plate.

\section{EXPERIMENTAL ANALYSIS}

The natural frequency of healthy composite beam with consider the relation of rotary inertia, shear deformation and damping.

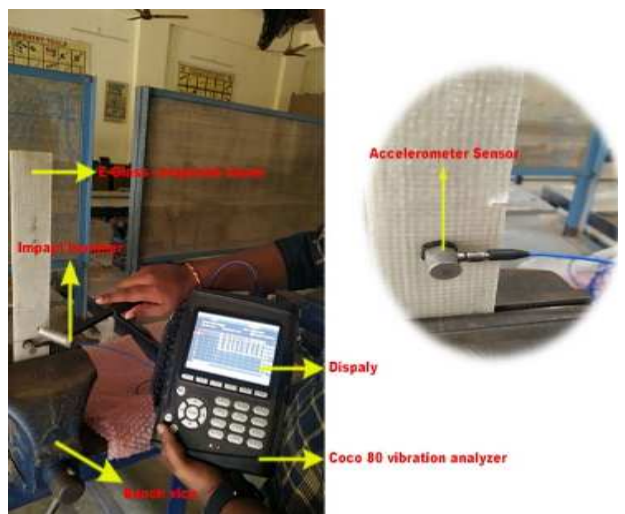

Fig. 1. Experimental analysis of E-Glass fiber beam 
The natural frequency of healthy composite beam with consider the relation of rotary inertia, shear deformation and damping. For vibrational center line of beam due to the component of displacement ' $\mathrm{V}$ 'and point of function $\mathrm{x}$, and time' $\mathrm{t}$ ' [20]:

$$
E I \frac{\partial^{4} V}{\partial X^{4}}+\rho A \frac{\partial^{2} V}{\partial t^{2}}=0 .
$$

With harmonic function of time consider as:

$$
V(x, t)=V(x) \sin (\omega t-a) .
$$

From equation (1) and (2):

$$
\begin{gathered}
\lambda^{4}=\frac{\rho A \omega^{2}}{E I}, \\
\frac{d^{4} V}{d x^{4}}+\lambda^{4} V=0,
\end{gathered}
$$

$V(x)=B_{1} \sinh \lambda x+B_{2} \cosh \lambda x+B_{3} \sin \lambda x+B_{4} \cos \lambda x .(5)$

The Eigen value $(\lambda)$ for composite beam at first three modes:

$$
\begin{gathered}
\left(\lambda_{1} L\right)=1.875, \\
\left(\lambda_{2} L\right)=4.694, \\
\left(\lambda_{3} L\right)=7.855, \\
\omega_{r}=\left(\lambda_{r}^{2}\right) \sqrt{\frac{E I}{\rho A}} ;(r=1,2,3) .
\end{gathered}
$$

An experimental modal investigation is performed on healthy composite beam for validation of numerical analysis carried using ANSYS ACP. One end of the composite healthy and crack beam of size $300 \times 50 \times 3$ $\mathrm{mm}$ is tightly fixed with the assistance of bench vice without damage the thickness of composite beam. Natural frequency test is carried out on healthy and cracked composite beam using impact hammer, accelerometer and FFT analyzer. Basically frequency range of composite material near to $1000 \mathrm{~Hz}$.As per setting available in FFT analyzer, $1440 \mathrm{~Hz}$ only available near to $1000 \mathrm{~Hz}$. Frequency range is selected from 0 to $1440 \mathrm{~Hz}$. The impact hammer sensitivity value is $10 \mathrm{mv} / \mathrm{g}$ and accelerometer sensor sensitivity is $9.6 \mathrm{mv} / \mathrm{g}$. The output channel is connected to the computer. An accelerometer is placed at the selected locations and initial excitation is given by the impact hammer and the output signal is saved in FFT analyzer. The data from FFT analyzer is transferred to EDM software for post processing of test results generated from equation 1-9. Figure 1 shows the experimental setup of E- Glass fiber beam for natural frequency test. Figure 2 shows modal frequencies of healthy composite beam. Figure 3 shows modal frequencies of an inclined cracked composite beam. Figure 4 shows modal frequencies of a longitudinal cracked composite beam. Figure 5 Shows modal frequencies from FFT analyzer for a transverse cracked composite beam. Table 1 represents experimental natural frequency data from FFT spectrum analyzer at crack location $150 \mathrm{~mm}$ from the fixed end.

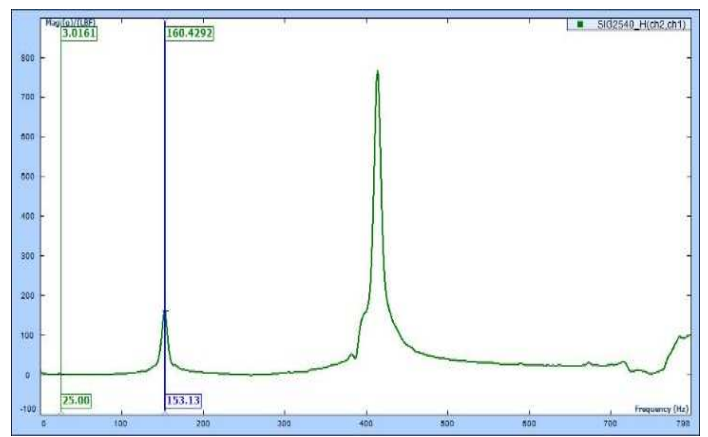

Fig. 2. Modal frequencies of healthy composite beam

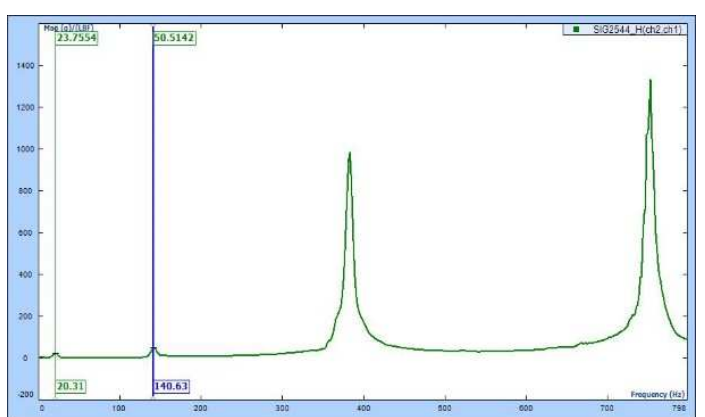

Fig. 3. Modal frequencies of an inclined cracked composite beam

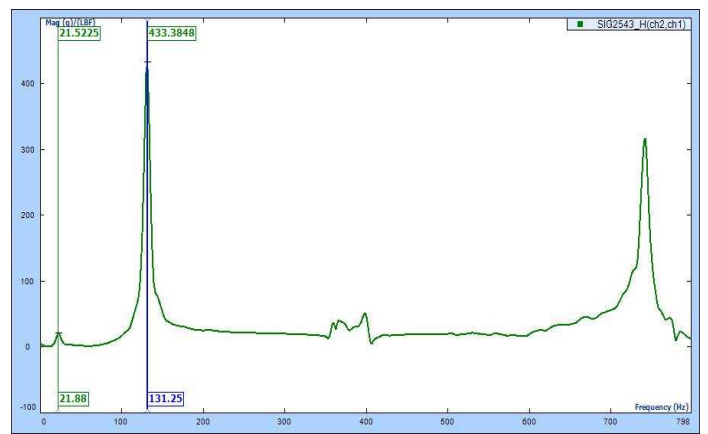

Fig. 4. Modal frequencies of an longitudinal cracked composite beam

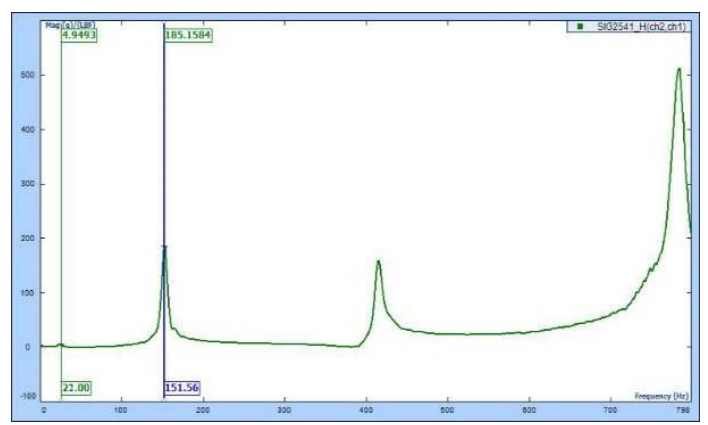

Fig. 5. Modal frequencies of an transverse cracked composite beam 
Tab. 1. Experimental natural frequency data from FFT analyzer at crack location $150 \mathrm{~mm}$ from the fixed end

\begin{tabular}{ccccc}
\hline Mode & $\begin{array}{c}\text { Healthy } \\
\text { beam } \\
{[\mathrm{Hz}]}\end{array}$ & $\begin{array}{c}\text { Inclined } \\
\text { crack } \\
{[\mathrm{Hz}]}\end{array}$ & $\begin{array}{c}\text { Longitudinal } \\
\text { crack } \\
{[\mathrm{Hz}]}\end{array}$ & $\begin{array}{c}\text { Transvers } \\
\text { e crack } \\
{[\mathrm{Hz}]}\end{array}$ \\
\hline 1 & 25.00 & 20.31 & 21.88 & 22.00 \\
\hline 2 & 153.3 & 140.8 & 131.25 & 151.56 \\
\hline 3 & 418.2 & 396.2 & 392.14 & 401.26 \\
\hline
\end{tabular}

\section{NUMERICAL ANALYSIS}

Modal analysis is performed using FEM software called ANSYS R3 2019 workbench to get first three modal frequencies of a healthy and cracked composite beams. A modal analysis used for determine the vibrational analysis of the composite beam. Figure 6 shows methodology for prediction of modal frequencies of a healthy and cracked composite beam using ANSYS ACP. In ACP preprocessing mode represent in block "A", composite beam geometry and a mesh, the boundary conditions and composite definitions are applied to composite beam in the preprocessing stage. After preprocessing data connect to input of solver block "B". In the post-processing mode block "c", after a completed solver and the transfer of the post-processing results can be evaluated. In this ANSYS ACP analysis blue lines indicated that data can be shared in between blocks and pink line mean data should be transfer one block to another block represent in Figure 6. Composite beam was modelled with 0/90 layups. Total 9 bi-directional layers of each $0.2 \mathrm{~mm}$ are used to model the composite beam. Table 2 shows specification of E-Glass composite beam and Table 3 shows the material behaviour of E-Glass composite material with epoxy used in the present modal analysis on healthy and cracked composite beam. After comparison it is confirmed that hexahedral elements generates more accurate results when compared with tetrahedral elements. Hexahedral element was used to generate the mesh for healthy and cracked composite beam. The mesh was converged with element size of $2 \mathrm{~mm}$. Figure 7 and 8 shows the orientation of fiber in composite beam and direction of layers in E-Glass composite beam respectively.

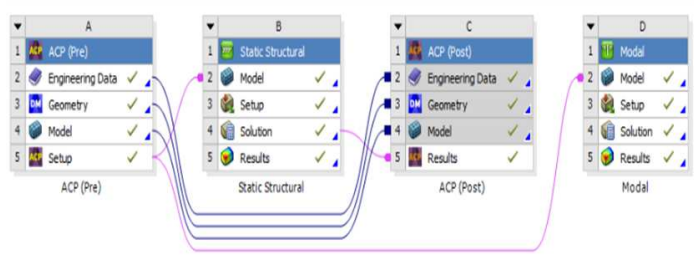

Fig. 6. Methodology for estimation of modal frequencies using ANSYS ACP

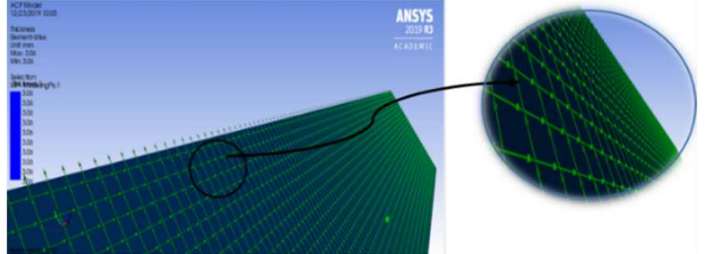

Fig. 7. Fiber orientation in composite beam

Table 4 shows the natural frequencies of healthy composite beam. Figure 9 and 10 shows the mode shapes of healthy and cracked composite beam respectively. Mode shapes cracked composite beam are changed when compared with healthy composite beam. So mode shapes also can be used to find the cracks present in the beam. Auto scale used to show the deformation in each mode. In red and blue colour indication in mode shape of both healthy and cracked composite are maximum and minimum deformation respectively. Table 5 depicts the results of first three natural frequencies of longitudinal crack, transverse crack and inclined crack with respect to change of crack location.

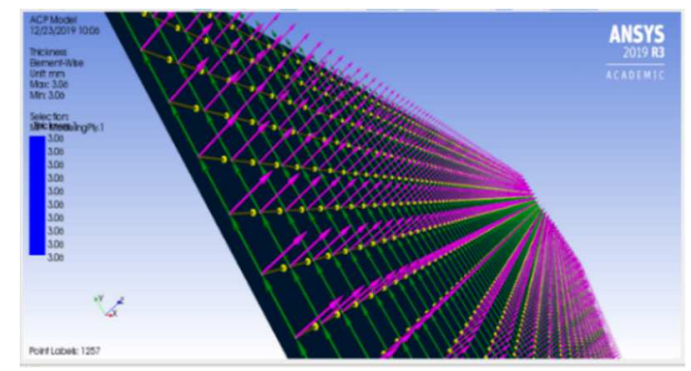

Fig. 8. Direction of layers in E-Glass composite beam

Tab. 2. Specification of E-Glass composite beam

\begin{tabular}{cc}
\hline Parameters & Value \\
\hline Total length & $300 \mathrm{~mm}$ \\
\hline Width & $50 \mathrm{~mm}$ \\
\hline Thickness & $3.05 \mathrm{~mm}$ \\
\hline No of layers & 9 \\
\hline Type of fiber & E-Glass fiber $(0.2 \mathrm{~mm}$ thickness $)$ \\
\hline Types of matrix & $\begin{array}{c}\text { Epoxy resin (LY556)\& } \\
\text { Hardener(HY951) }\end{array}$ \\
\hline Direction of ply & $(0 / 90)$ \\
\hline
\end{tabular}

Tab. 3. Material behaviour of E-Glass composite beam

\begin{tabular}{cc}
\hline Material properties & Value \\
\hline Young's modulus $\left(\mathrm{E}_{\mathrm{x}}\right)$ & $35125 \mathrm{MPa}$ \\
\hline Young's modulus $\left(\mathrm{E}_{\mathrm{Y}}\right)$ & $6450 \mathrm{MPa}$ \\
\hline Young's modulus $\left(\mathrm{E}_{\mathrm{Z}}\right)$ & $6450 \mathrm{MPa}$ \\
\hline Shear modulus $\left(\mathrm{G}_{\mathrm{xy}}\right)$ & $2436 \mathrm{MPa}$ \\
\hline Shear modulus $\left(\mathrm{G}_{\mathrm{yz}}\right)$ & $1696 \mathrm{MPa}$ \\
\hline Shear modulus $\left(\mathrm{G}_{\mathrm{zx}}\right)$ & $2436 \mathrm{MPa}$ \\
\hline Poisson's ratio $\left(v_{\mathrm{xy}}\right)$ & 0.223 \\
\hline Poisson's ratio $\left(v_{\mathrm{xz}}\right)$ & 0.223 \\
\hline Poisson's ratio $\left(v_{\mathrm{yz}}\right)$ & 0.372 \\
\hline
\end{tabular}




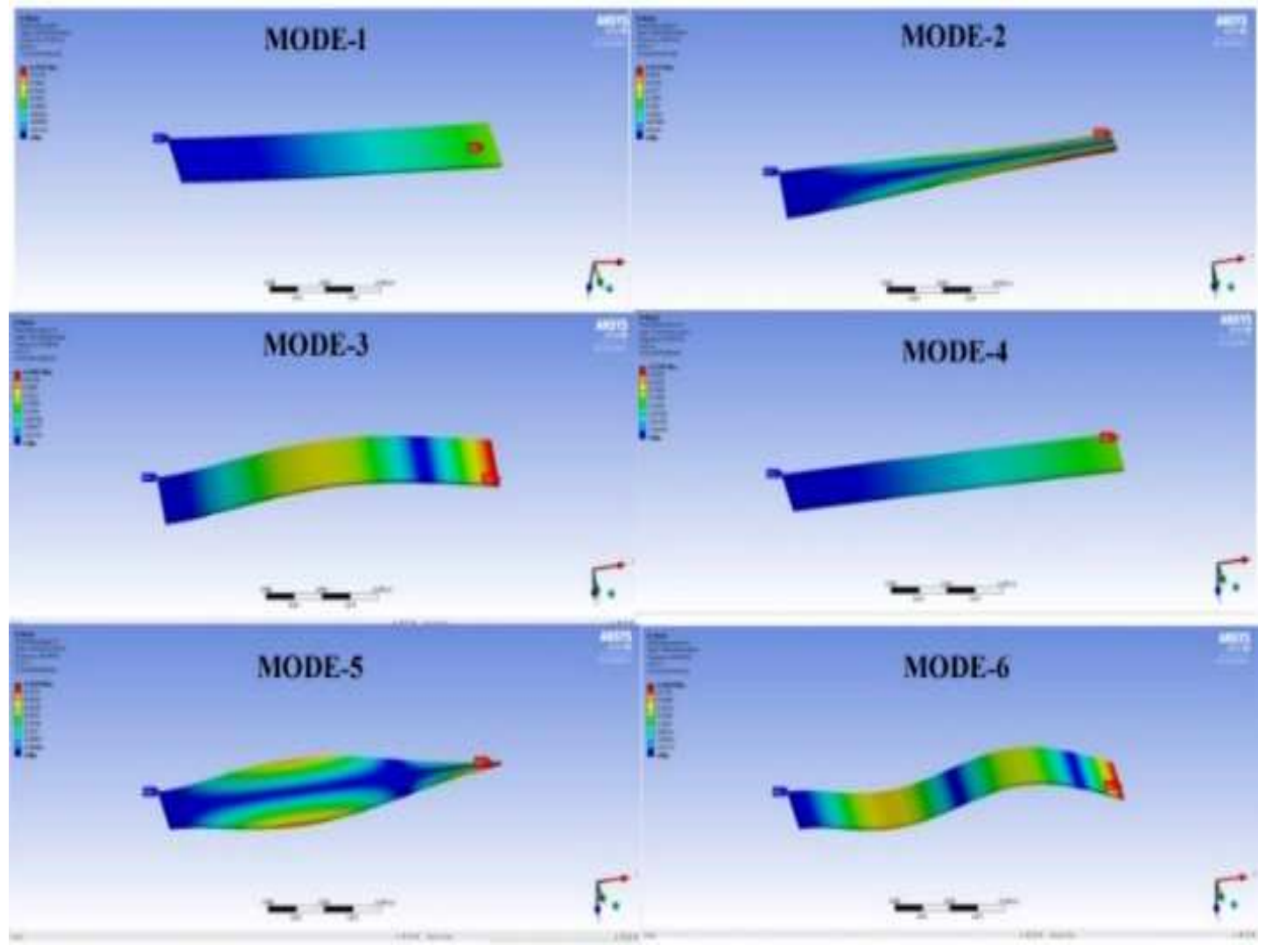

Fig. 9. Mode shapes for healthy composite beam
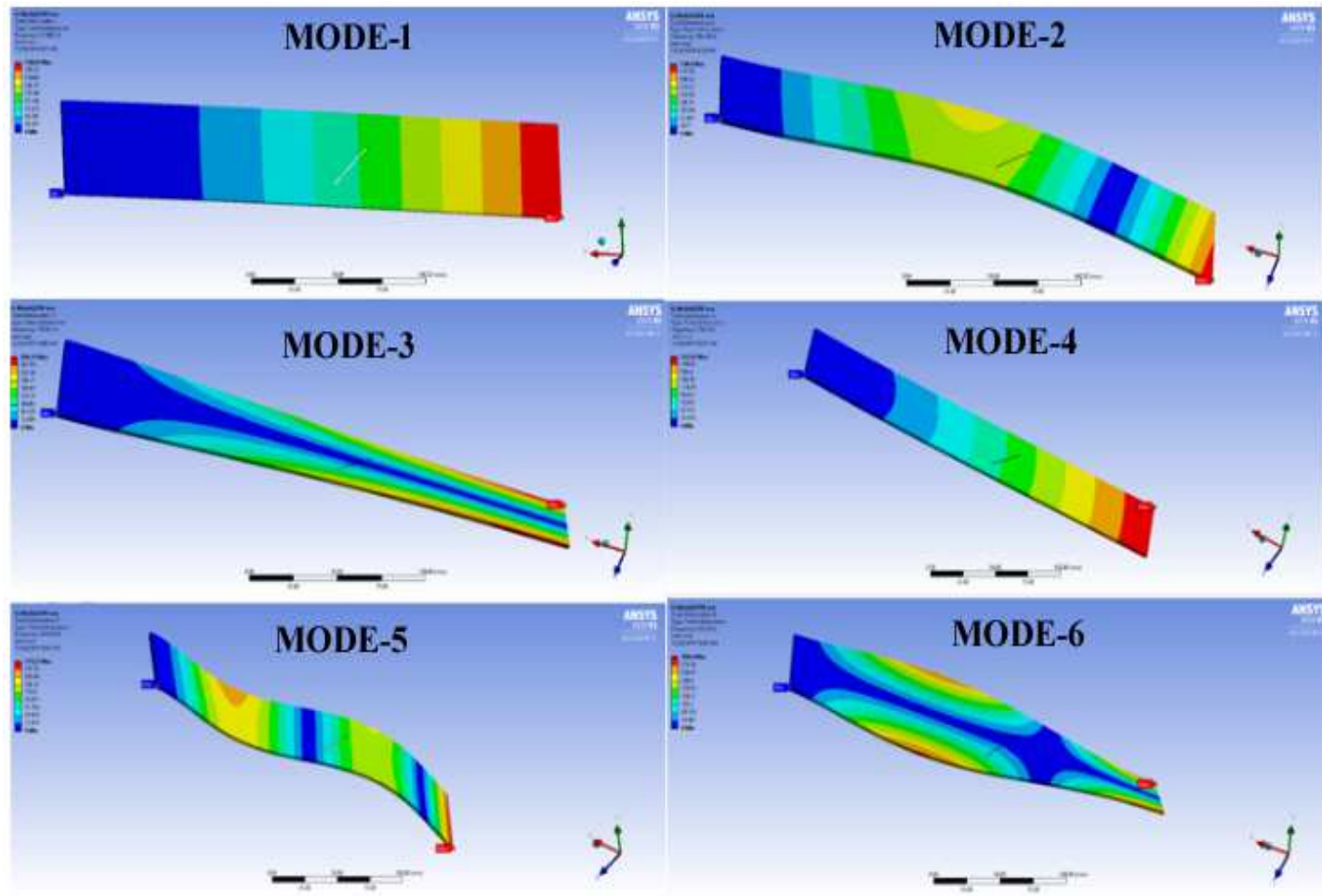

Fig. 10. Mode shapes for cracked composite beam 
Tab. 4. Natural frequency of cracked composite

\begin{tabular}{|c|c|c|c|c|c|c|c|c|c|}
\hline \multirow[t]{2}{*}{$\begin{array}{c}\text { Crack } \\
\text { location } \\
{[\mathrm{mm}]}\end{array}$} & \multicolumn{3}{|c|}{$\begin{array}{l}\text { Longitudinal crack } \\
\qquad[\mathrm{Hz}]\end{array}$} & \multicolumn{3}{|c|}{$\begin{array}{c}\text { Transverse crack } \\
{[\mathrm{Hz}]}\end{array}$} & \multicolumn{3}{|c|}{$\begin{array}{c}\text { Inclined crack } \\
{[\mathrm{Hz}]}\end{array}$} \\
\hline & $f_{1}$ & $f_{2}$ & $f_{3}$ & $f_{1}$ & $f_{2}$ & $f_{3}$ & $f_{1}$ & $f_{2}$ & $f_{3}$ \\
\hline 50 & 21.83 & 148.68 & 170.61 & 23.89 & 149.94 & 170.68 & 21.83 & 148.68 & 170.63 \\
\hline 100 & 23.66 & 146.27 & 169.70 & 23.93 & 149.94 & 170.82 & 22.79 & 145.84 & 170.66 \\
\hline 150 & 23.77 & 145.38 & 170.14 & 23.94 & 149.86 & 171.00 & 23.49 & 138.88 & 170.98 \\
\hline 200 & 23.86 & 145.39 & 170.56 & 23.96 & 149.78 & 171.19 & 23.85 & 141.49 & 171.31 \\
\hline 250 & 23.98 & 148.37 & 171.21 & 23.99 & 149.81 & 171.43 & 23.99 & 148.44 & 171.58 \\
\hline
\end{tabular}

Tab. 5. Natural frequencies of healthy composite beam

\begin{tabular}{cc}
\hline Mode shape number & Modal frequency $[\mathrm{Hz}]$ \\
\hline 1 & 24.802 \\
2 & 130.22 \\
3 & 169.59 \\
4 & 309.39 \\
5 & 364.15 \\
6 & 522.49 \\
\hline
\end{tabular}

\section{RESULTS AND DISCUSSIONS}

FFT modal analysis is used for conducted composite healthy beam and different types of inclined, longitudinal, and transverse cracked beams. Damage present in the composite beam can be identified by change of natural frequency between healthy and cracked composite beam. First three frequencies are sufficient to estimate the damage present in the cracked composite beam. The natural frequency is majorly influenced by crack direction and crack area from fixed side of composite beam. In the present study crack is generated at distance of $200 \mathrm{~mm}$ from the fixed end in the composite beam. Figure 11 shows the comparison of modal frequencies obtained from FFT modal analysis. From figure 11, it was observed that natural frequency of healthy composite beam is greater than cracked beams. Figure 12 shows comparison between the modal analysis of composite healthy beam. From the figure 12 shows comparison between the experimental and numerical healthy beam. From the figure 12 clearly shows that the maximum percentage of error is $9.486 \%$. Figure 13 shows comparison between the experimental and numerical composite cracked beam. From the figure 13 clearly shows that the maximum percentage of error is $3.286 \%$. From the figure 12, third modal frequency of composite beam $(418.2 \mathrm{~Hz})$ is same as fifth modal frequency (364.15) of Table 5.

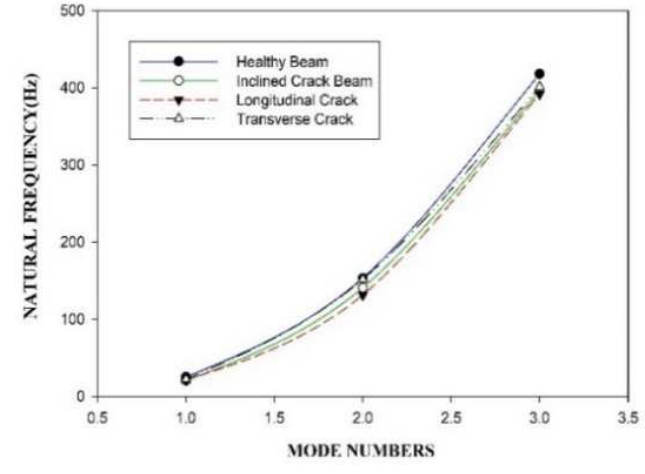

Fig. 11. Comparison of modal frequencies

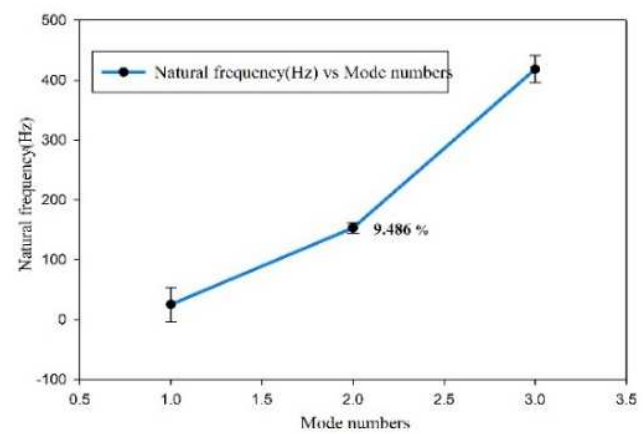

Fig. 12. Comparison between the modal analysis of composite healthy beam

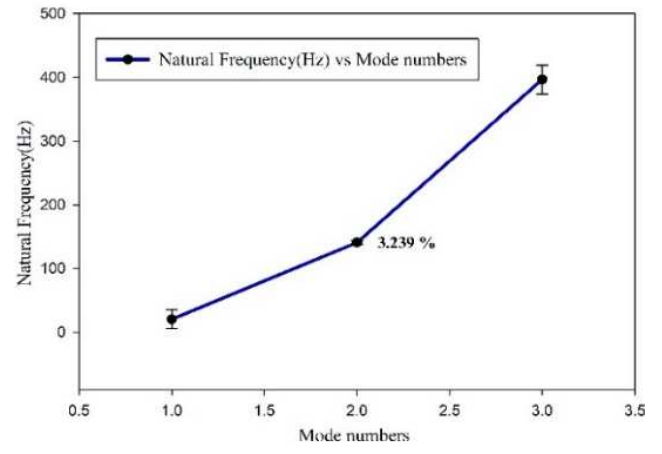

Fig. 13. Comparison between the modal analysis of composite cracked beam 


\subsection{Residual Life Criteria and $\mathbf{S}-\mathbf{N}$ Curves}

The equation used for determine the residual life of composite beam [21]. The figure 14 shows the S-N curve generated for healthy E-Glass composite beam using Eqs.5

Hwang and Han's relation:

$$
N=(B(1-r))^{\frac{1}{c}},
$$

where: $B=10.33$ and $C=0.14012$.

Applied stress level $(r)$ is ratio of maximum stress to ultimate tensile stress [MPa] of composite beam:

$$
\sigma_{\max }=\frac{6 f l}{b t^{2}}
$$

A load of $1000 \mathrm{~N}$ is applied on the residual life of composite beam. Residual life of healthy composite beam, inclined composite cracked beam, longitudinal composite cracked beam and transverse cracked composite beam calculated using Hwang and Han's equation 10 and 11 . Residual life of healthy composite beam is $15.72 \times 10^{6}$ cycles, inclined composite cracked beam is $12.04 \times 10^{6}$ cycles, longitudinal composite cracked beam is $15.46 \times 10^{6}$ cycles and transverse composite cracked beam is $11.04 \times 10^{6}$ cycles

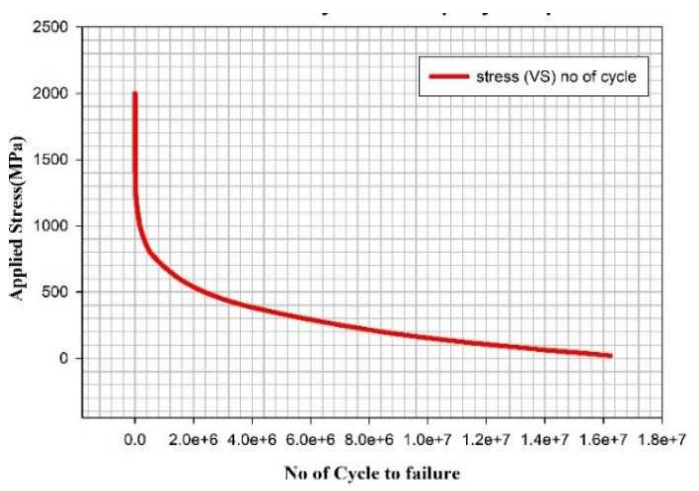

Fig. 14. S-N curve for healthy E-Glass composite beam

\section{CONCLUSIONS}

Residual life of healthy and cracked composite beam are estimated using experimental and numerical modal analysis methods.

1. A good correlation is observed between experimental and numerical modal analysis results.

2. The natural frequency of the E-Glass composite beam is directly proportional to stiffness of the composite beam i.e. high modal frequency reflects that high stiffness of composite beam

3. The natural frequency of a composite beam decreases when crack orientation increased to fixed end position.

4. The numerical results are validated for natural frequency of composite beam with benchmark solutions of Pushparaj et al. [6] and found to be in decent agreement with maximum percentage of deviation $17.89 \%$.

5. To enhancement in first modal frequency at crack constant crack location $150 \mathrm{~mm}$ from the fixed end (from $23.49 \mathrm{~Hz}$ to $23.94 \mathrm{~Hz}$ ) occurs at the different crack orientations.

6. From the analysis of residual life estimation of different crack orientation beams it was found that transverse cracked beam has least residual life when compared with longitudinal crack and inclined cracked beam.

From the numerical analysis using ANSYS R3 2019 workbench it was found that the residual life of healthy composite beam is $15.72 \times 10^{6}$ cycles, longitudinal composite cracked beam is $15.46 \times 10^{6}$ cycles, inclined composite cracked beam is $12.04 \times 10^{6}$ cycles and transverse composite cracked beam is $11.04 \times 10^{6}$ cycles.

\section{Nomenclature}

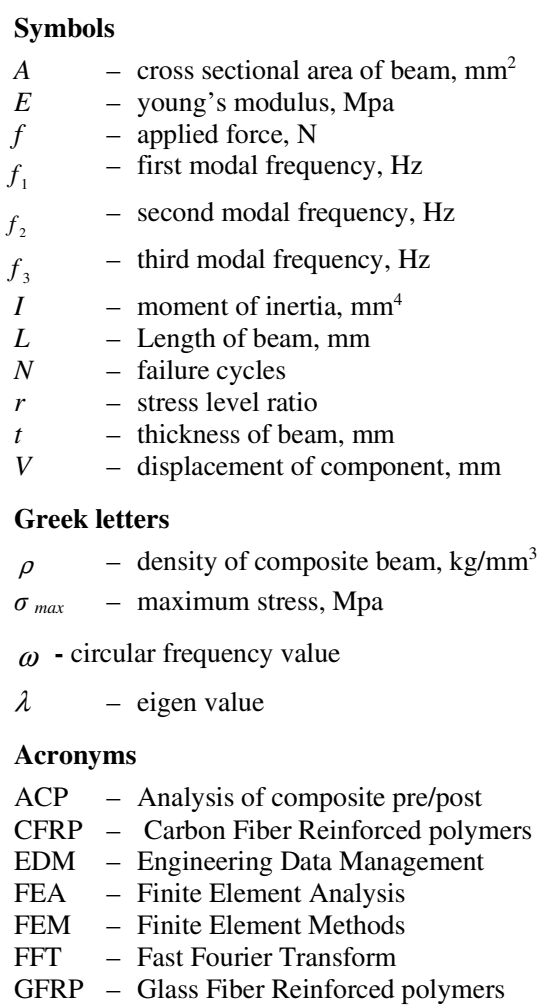

\section{References}

1. Pratibha ,M Karandikar V. V. (2016). Experimental Investigation of crack dection of cantilever beam . IOSR Journal of Mechanical and Civil Engineering, Vol. 13, pp.12-17.

2. C. Santiuste, S. Sanchez-Saez and E. Barbero.(2010). Residual flexural strength after low-velocity impact in glass/polyester composite beams. Composite Structures, Vol. 92, pp. 25-30.

3. S. Chakraborty, M. Mukhopadhyay and A. R. Mohanty. (2000). Free Vibrational Responses of FRP Composite Plates: Experimental and numerical studies. Journal of 
Reinforced Plastics and Composites, Vol. 19, pp.535551.

4. Bilel Aidi, Mohamed Shaat, Abdessattar Abdelkefi and Scott W case .(2017). Free vibration analysis of cantilever open hole composite plates. Meccanica,Vol.52, PP.2819-2836.

5. Cui Yanbin, shi Lei, Zhao Feng. (2010). Modal analysis of wind turbine blade made of composite laminate plates. In:Asia-Pacific Power and Energy Engineering Conference APPEEC2010, Chengdu, China, 28-31 March 2010..

6. Pushparaj Pingulkar and Suresha B. (2016). Free vibration analysis of laminated composite plates using finite element method. Polymers \& polymer composites, Vol. 24, pp.529-538.

7. Mishra, S. K. (2015). Modal analysis of woven fiber composite plates with different boundary conditions. International Journal of Structural Stability and Dynamics, Vol. 15, pp.1-17.

8. R.R. Chaudhari, Y. F. (2015). vibration analysis of laminated triangular plate by experimental and finite element analysis. International Journal of Engineering Research and General Science, Vol. 3, pp.786-791.

9. More, A. S. (2016). Vibration analysis of cracked cantilever beam. International Research Journal of Engineering and Technology, Vol. 3, pp.1171-1181.

10. Sharayu U. Ratnaparkhi, S. S. (2013). vibration analysis of composite plate. International Journal of Modern Engineering Research, Vol. 6, pp.377-380.

11. Reddy, P. N. (2018). An Analysis of Composite Drive Shaft Using ANSYS ACP. International Journal of Mechanical and Production Engineering Research and Development, Vol. 8, pp.117-124.

12. Soham S. Vader, V. A. Raikar. (2017) Crack detection in composite cantilever beam by vibration analysis and numerical method. International Research Journal of Engineering and Technology, vol. 4, pp. 1776-1784.

13. Mirko S. Maksimovic, I. V. (2018). Residual life estimation of cracked aircraft structural components. FME Transactions, Vol. 46, pp.124-128.

14. $\mathrm{Xu}$ lei, Wang Rui, Zhang Shujie and Liu Yong.(2011).Vibration characteristics of glass fabric/ epoxy composites with different woven structures. Journal of composite materials, Vol. 45, pp.1069.

15. Kale Dipak R, R.R.Arakerimath.(2020).Natural frequency for a composite structure made with a combination of metal and laminated composites. International Journal of Recent Technology and Engineering, Vol. 8, pp. 2340-2344, 2020.

16. Y.L. Hu, E. Madenci. (2017). Peridynamics for fatigue life and residual strength prediction of composite laminates. Composite Structures, Vol. 160, pp.169-184.

17. Prenil Poulose , Zhong Hu. (2010). Strength evaluation and failure predication of a composite wind turbine blade using FEA. In: Proceeding of the ASME International Mechanical Engineering Congress and Exposition IMECE2010, British Columbia, Canada, 1218,November, pp.1-7.

18. A R A Syayuthi, M S Abdul Majid, M J M Ridzuan, K S Basaruddin, Peng, T L.(2017). Effect of stress ratio on the fatigue behaviour of glass/epoxy composite, In: International Conference on Applications and Design in Mechanical Engineering (ICADME 2017), Penang, Malaysia, 21-22, August, pp. 1-6.

19. Wei Lian, Weixing Yao.(2010). Fatigue life prediction of composite laminates by FEA simulation method. International Journal of Fatigue, Vol. 32, pp.123-133.

20. Roberto Capozucca. (2014). vibration of CFRP Cantilever Beam with Damage. Composite structure. DOI: http://dx.doi.org/10.1016/j.compstruct.2014.04.027
21. Padmanabhan, A. b. (2014). Design for Fatigue and simulation of glass fiber/epoxy composite automobile leaf spring. ARPN Journal of Enginnering and Applied Science, Vol. 9, No.3, pp.196-203.

\section{Biographical notes}

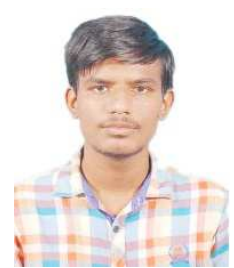

Gedela Ramprasad studying M.Tech degree (Computer aided analysis and design) specialization in Gayatri Vidya Parishad College of Engineering (Autonomous), Visakhapatnam, Andhra Pradesh, India. Areas of interests: Composites, Computational Fluid dynamics, Design, Manufacturing and Vibration analysis.Published 2 international research papers and 1 national conferences.

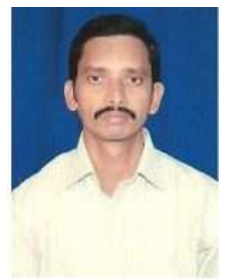

Dr.S.Ramakrishna Assoc.Professor at Gayatri Vidya Parishad College of Engineering (Autonomous), Visakhapatnam, Andhra Pradesh, India. Areas of interests: Composites, Computational Fluid dynamics, Design, and Vibration analysis. Published 37 international research journal papers and 39 national/international conferences. Also published one patent in the area of composites. 